\title{
Densidades de plantas de Urochloa decumbens em convivência com Corymbia citriodora
}

\section{Plant densities of Urochloa decumbens in coexistence with Corymbia citriodora}

\author{
Maria Renata Rocha Pereira ${ }^{1 *}$; Guilherme Sasso Ferreira Souza ${ }^{2}$; Jose Iran \\ Cardoso Silva ${ }^{3}$; Dagoberto Matins ${ }^{4}$
}

\section{Resumo}

O presente estudo teve como objetivo avaliar os efeitos da convivência de densidades crescentes de plantas Urochloa decumbens no crescimento inicial de plantas de Corymbia citriodora. O delineamento experimental adotado foi inteiramente casualisado, com quatro repetições; cada parcela constou de um vaso de $60 \mathrm{~L}$ de capacidade. As densidades de capim-braquiária foram: 0, 20, 40, 80 e 160 plantas $\mathrm{m}^{-2}$, juntamente com uma planta de eucalipto. Foram realizadas, ao final de oito meses de convivência, as avaliações de: incremento em altura e em diâmetro e massa seca das plantas de eucalipto e de capimbraquiária. Para todas as características estudadas a população infestante influenciou no desenvolvimento das plantas de eucalipto, sendo o efeito mais acentuado à medida que se aumentou a densidade de plantas de capim-braquiária.

Palavras-chave: Capim-braquiária, eucalipto, matocompetição, matointerferência

\begin{abstract}
This study aimed to evaluate the effects of plant densities of Urochloa decumbens on the early growth of Corymbia citriodora. The experimental design was completely randomized design with four replications, each plot consisted of a of $60 \mathrm{~L}$ capacity vase. The signal grass densities were $0,20,40$, 80 and 160 plants $\mathrm{m}^{-2}$, along with one eucalyptus plant. At the end of eight months of living together increase in height and in diameter and plant dry mass of eucalyptus and signal grass were carried out. The eucalyptus characteristics were influenced by all the weed populations, the effect being more pronounced with the increasing of grass density.
\end{abstract}

Key words: Brachiaria, eucalyptus, weed competition, weed interference

\section{Introdução}

A implantação de maciços florestais de rápido crescimento constitui-se na alternativa mais viável e promove uma grande oferta de madeira para atender a demanda do mercado brasileiro e mundial, além de proteger as reservas naturais.

O eucalipto continua sendo a espécie florestal mais plantada no Brasil. Em 2010, a área ocupada por plantios florestais de Eucalyptus e Pinus no Brasil totalizou mais de 6,5 milhões de hectares,

\footnotetext{
1 Engenheira Florestal, Pós-doutoranda em Agronomia da Faculdade de Ciências Agronômicas, UNESP. C P 237, 18603-970, Botucatu, SP. E-mail: mariarenata10@hotmail.com

2 Eng ${ }^{\mathrm{o}}$ Agr $^{\circ}$, Doutorando em Agronomia da UNESP, Botucatu, SP. E-mail: guisasso@hotmail.com

3 Eng ${ }^{\circ}$ Agr $^{\circ}$, Pós-doutorando em Agronomia na Universidade Federal do Tocantins, UFTO, Gurupi, TO. E-mail: joseiranc@ hotmail.com

4 Prof. Dr. da Faculdade de Ciências Agronômicas, UNESP, Botucatu, SP. E-mail: dmartins@fca.unesp.br

* Autor para correspondência
} 
sendo $73,0 \%$ correspondente à área de plantios de Eucalyptus. A maior concentração de plantios florestais ocorre nas regiões sul e sudeste do país $(75,2 \%)$, onde também estão localizadas as principais unidades industriais dos segmentos de celulose, papel, painéis de madeira industrializada e siderurgia a carvão vegetal, mas já existe o incentivo da migração da atividade florestal para áreas denominadas de "novas fronteiras florestais", onde se observa o aumento dos plantios de Eucalyptus, como o caso dos estados do Mato Grosso do Sul e Maranhão, em que o crescimento da área de plantios de Eucalyptus, entre 2009 e 2010, aumentou em $30,0 \%$ e $10,2 \%$, respectivamente. (ABRAF, 2011).

A madeira do Corymbia citriodora Hill \& Johnson (Eucalyptus citriodora Hook), espécie utilizada no presente estudo, possui múltiplas finalidades como para construções, estruturas, caixotaria, postes, dormentes, mourões, lenha e carvão, além da produção de óleos e taninos. Apresenta susceptibilidade à geadas, mas tem boa resistência à deficiência hídrica, sendo uma alternativa para os novos plantios em área, com temperaturas médias elevadas e com precipitação deficiente em algumas épocas do ano, como é o caso do Maranhão, já citado anteriormente, pois deve-se considerar as geadas como fator limitante para esta espécie (IPEF, 2004).

As culturas florestais, como qualquer população natural, estão sujeitas a uma série de fatores ecológicos que, direta ou indiretamente, podem afetar o crescimento de árvores e, conseqüentemente, a produção de madeira, carvão e celulose. Segundo Toledo et al. (1996), na implantação de uma área de Eucalyptus grandis no Brasil a atividade mais onerosa no primeiro ano é o controle de plantas daninhas.

A intensidade de competição por fatores ambientais como água, nutrientes e luz pode limitar o crescimento das plantas e depende diretamente da densidade populacional do eucalipto e da comunidade infestante de plantas daninhas (SILVA et al., 2008). Silva et al. (2004) observaram que a convivência de Urochloa brizantha com $C$. citriodora ou E. grandis reduziu o acúmulo de biomassa seca do eucalipto. Segundo os autores, este fato pode ser explicado pela presença das plantas daninhas nas áreas cultivadas que reduziu a produtividade, tanto pela competição direta pelos fatores de produção, quanto pela interferência indireta sobre as plantas cultivadas, como ocorre no caso da alelopatia.

Em grande parte das áreas florestais, as populações das plantas infestantes atingem elevadas densidades populacionais e passam a condicionar fatores que são negativos ao crescimento e produtividade das árvores e à operacionalização do sistema produtivo (MARCHI et al., 2002). Cantarelli et al. (2006) observaram em região de várzea diferenças significativas entre os tratamentos de controle químico e o sem controle em plantações de Pinus taeda L., concluindo que é benéfico o controle das plantas daninhas por dois anos.

Dentre os métodos disponíveis para o controle das plantas daninhas na cultura do eucalipto se destaca na linha de cultivo o controle químico, com a utilização de herbicidas, enquanto na entrelinha o controle mecânico, pelo uso de roçadeira, é o método mais utilizado. Devido à escassez de produtos registrados à cultura para controle seletivo em pós-emergência das plantas daninhas, o uso do controle químico deve ser muito cauteloso evitando causar injúrias à cultura (AGOSTINETTO et al., 2010). De acordo com Pereira et al. (2011) a deriva do herbicida glyphosate em doses acima de $80 \mathrm{~g}$ de equivalente ácido ha-1 pode afetar negativamente o crescimento do eucalipto, bem como apresentar sintomas de fitotoxicidade de ate $70 \%$. Assim, o conhecimento da matocompetição na cultura do eucalipto é de grande relevância para que se determine a quantidade de plantas daninhas que podem conviver com a cultura, sem causar prejuízos, para que a aplicação de herbicidas seja diminuída. 
Uma das espécies de plantas daninhas mais importantes em áreas de reflorestamento é o capimbraquiária (Urochloa decumbens Stapf), já que esta espécie foi introduzida como forrageira, e ao transformar estas áreas em lavouras, o capimbraquiária passa a se constituir numa importante infestante, muito agressiva e de difícil controle (KISSMANN, 1997). Esta espécie é resistente à seca, adaptando-se bem em regiões tropicais úmidas, pouco tolerantes ao frio e cresce bem em diversos tipos de solo, vegetando bem em terrenos arenosos e argilosos, sendo assim uma espécie com grande capacidade competitiva e, também possui efeito alelopático sobre plantas de Eucalyptus, reduzindo significativamente seu crescimento inicial (CONSTANTIN; OLIVEIRA JUNIOR; MACIEL, 2000). De acordo com Toledo et al. (2001), 4 plantas de $U$. decumbens $\mathrm{m}^{-2}$ são suficientes para reduzir o crescimento de plantas de E. grandis, nos primeiros 90 dias após transplantio. É necessário verificar se este comportamento ocorre em uma convivência por um maior tempo, pois as espécies de Eucalyptus são de rápido crescimento tanto em parte aérea como radicular, podendo assim não sofrer com a matocompetição a partir de uma certa idade.

O presente estudo teve por objetivo avaliar os efeitos da interferência de densidades crescentes de plantas de $U$. decumbens sobre o crescimento inicial de plantas de Corymbia citriodora).

\section{Material e Métodos}

O experimento foi realizado no município de Botucatu/SP, nos meses de junho de 2009 a fevereiro de 2010, com temperaturas médias de $18^{\circ} \mathrm{C}$ e $25^{\circ} \mathrm{C}$. Nos meses de junho a outubro o experimento foi irrigado, devido à precipitação deficiente, de acordo com os dados de potencial de água no solo através de tensiômetros, até atingir a tensão de -0,03 MPa.

Os tratamentos foram constituídos de cinco densidades de plantas de $U$. decumbens (capim- braquiária) 0, 20, 40, 80 e 160 plantas $\mathrm{m}^{-2}$, em convivência com uma planta de Corymbia citriodora em vasos plásticos com $60 \mathrm{~L}$ de capacidade.

As plantas de capim-braquiária, que estavam em média com $10 \mathrm{~cm}$ de altura, foram transplantadas para os vasos preenchidos com solo aos 15 dias após o transplantio das mudas de $C$. citriodora e, estas estavam em média com $30 \mathrm{~cm}$ de altura. A densidade populacional do capim-braquiária foi mantida durante todo experimento através da eliminação de outras espécies de plantas daninhas.

As mudas de capim-braquiária foram cultivadas em bandeja de isopor com células contendo o substrato comercial Plantimax, o mesmo utilizado nos tubetes para a produção das mudas de $C$. citriodora, estas de origem clonal. O delineamento experimental utilizado foi o inteiramente casualizado, com quatro repetições.

O solo utilizado foi classificado de acordo com o novo Sistema Brasileiro de Classificação de Solos (EMBRAPA, 1999) e denominado de Latossolo Vermelho Distróférrico típico de textura argilosa (50,4\% de argila, $25,7 \%$ de silte e $23,9 \%$ de areia). Este foi seco à sombra, peneirado em malha de 5 $\mathrm{mm}$ e a adubação para o plantio foi realizada de acordo com a análise química do solo (Tabela 1), utilizando $30 \mathrm{~kg} / \mathrm{ha}$ de $\mathrm{N}, 60 \mathrm{~kg} / \mathrm{ha}$ de $\mathrm{P}$ e $30 \mathrm{~kg} / \mathrm{ha}$ através de adubo químico N-P-K na formulação 04-14-08. A adubação de cobertura foi realizada com $10 \mathrm{~kg} / \mathrm{ha}$ de $\mathrm{N}$ e $10 \mathrm{~kg} / \mathrm{ha}$ de $\mathrm{K}$, realizada em duas aplicações, no $2^{\circ}$ e $4^{\circ}$ mês de experimento à 5 cm da muda, sendo incorporado após a aplicação.

Em razão da baixa fertilidade natural do solo, foi feita correção com calcário dolomítico com PRNT igual a 91\%. Empregou-se o método de saturação por bases (V\%) (RAIJ et al., 1997) para o cálculo de necessidade de calagem, visando aumentá-la para $70 \%$. O calcário foi misturado homogeneamente com o solo, que foi deixado em incubação úmida a aproximadamente $60 \%$ da capacidade de retenção de água por 30 dias. 
Tabela 1. Análise química de fertilidade do solo utilizado nos estudos. Botucatu/SP. 2009/2010.

\begin{tabular}{ccccccccc}
\hline PH & M.O. & P resina & \multicolumn{4}{c}{$\mathbf{m m o l ~ d m}^{-3}$} & & V (\%) \\
$\mathrm{CaCl}_{2}$ & $\mathbf{g ~ d m}^{-3}$ & $\mathbf{~ m g ~ d m}^{-3}$ & $\mathbf{H}+\mathbf{A l}$ & $\mathbf{K}$ & $\mathbf{M g}$ & $\mathbf{S B}$ & $\mathbf{C T C}$ & \\
\hline 5,2 & 24 & 34 & 5,3 & 28 & 19 & 53 & 87 & 61 \\
\hline
\end{tabular}

Ao final do experimento foram avaliadas as seguintes características: incremento em altura e em diâmetro (altura/diâmetro das plantas após 240 dias - altura/diâmetro das plantas no momento de transplantio) e massa seca das plantas de $C$. citriodora (parte aérea total) e de capim-braquiária, em estufa de circulação forçada de ar, a $60^{\circ} \pm 2^{\circ} \mathrm{C}$ por 72 horas.

Os resultados foram submetidos à análise de variância pelo teste $\mathrm{F}$ e a análise de regressão foi realizada pelo programa Sisvar, sendo as equações ajustadas, e adotou-se os modelos de regressão linear e polinomial.

\section{Resultados e Discussão}

Aos oito meses após o transplantio das mudas de $C$. citriodora, observaram-se altas reduções no incremento em altura das plantas submetidas aos tratamentos em comparação às plantas testemunhas, como pode ser verificado pela queda na curva de regressão (Figura 1), sendo de 32\% nas plantas em convivência com 20 e 40 plantas de $U$. decumbens $\mathrm{m}^{-2}$ (Tabela 2), não havendo diferenças entre estes dois tratamentos, ficando assim o crescimento em altura das plantas de C. citriodora comprometido a partir da convivência deste com 20 plantas $\mathrm{m}^{-2}$.

Figura 1. Efeito de densidades de plantas $U$. decumbens sobre o incremento em altura de plantas de $C$. citriodora avaliado aos 240 dias após o plantio. Botucatu/SP, 2009/2010.

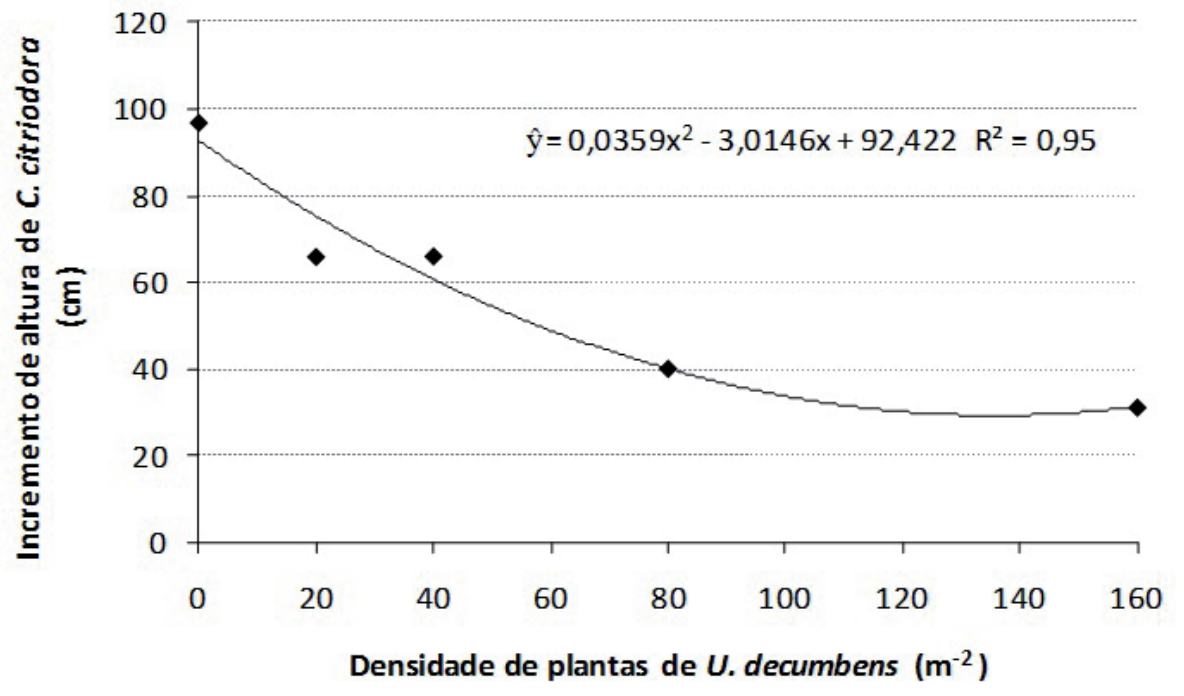

As plantas de C. citriodora submetidas à convivência com 80 plantas de $U$. decumbens $\mathrm{m}^{-2}$ tiveram seu incremento em altura reduzido em 58,7\% e, com 160 plantas $\mathrm{m}^{-2}$ em $68 \%$ (Tabela 2). Pode-se inferir que não há diferenças na competição do eucalipto com 80 plantas $\mathrm{m}^{-2}$ e 160 plantas $\mathrm{m}^{-2}$ de $U$. decumbens, já que mesmo duplicando a densidade de plantas de capimbraquiária, a redução do incremento não evoluiu na mesma proporção. Este fato pode ser observado na curva de regressão (Figura 2), visto que esta se estabiliza a partir de 80 plantas $\mathrm{m}^{-2}$ de $U$. decumbens, indicando uma possível competição intraespecífica. 
Tabela 2. Valores médios dos parâmetros avaliados por planta de C. citriodora e U. decumbens. Botucatu/ SP, 2009/2010.

\begin{tabular}{|c|c|c|c|c|}
\hline $\begin{array}{l}\text { Densidades de } \\
\text { U. decumbens }\left(\mathrm{m}^{-2}\right)\end{array}$ & $\begin{array}{c}\text { Incremento em } \\
\text { Altura (cm) }\end{array}$ & $\begin{array}{l}\text { Incremento em } \\
\text { diâmetro (mm) }\end{array}$ & $\begin{array}{c}\text { Massa Seca } \\
\text { C. citriodora (g) }\end{array}$ & $\begin{array}{c}\text { Massa Seca } \\
\text { U. decumbens (g) }\end{array}$ \\
\hline 0 & $97,0 \quad \mathrm{~A}$ & 11,68 a & $109,5 \quad \mathrm{a}$ & $\begin{array}{ll}0 & \mathrm{~d}\end{array}$ \\
\hline 20 & $66,0 \mathrm{Ab}$ & $6,99 \quad b$ & 77,2 & 22,49 \\
\hline 40 & $66,2 \mathrm{Ab}$ & $6,82 \quad b$ & 53,7 & 18,94 \\
\hline 80 & $40,2 \mathrm{~B}$ & 4,34 bc & 39 & 18,66 \\
\hline 160 & $31,1 \quad \mathrm{~B}$ & $2,72 \quad \mathrm{c}$ & $25 \quad \mathrm{~d}$ & $13,88 \quad \mathrm{c}$ \\
\hline $\mathrm{F}_{\text {tratamentos }}$ & $9,256^{* *}$ & $13,881 * *$ & $75,293 * *$ & $424,285 * *$ \\
\hline CV $(\%)$ & 28,3 & 28 & 12,62 & 5,79 \\
\hline d.m.s & 37,1 & 3,98 & 16,78 & 1,87 \\
\hline
\end{tabular}

Médias seguidas de mesma letra na coluna, não diferem estatisticamente entre si pelo teste Tukey $(\mathrm{p}<0,05)$.

**- Significativo ao nível de $1 \%$ de probabilidade.

Figura 2. Efeito de densidades de plantas $U$. decumbens sobre o incremento em diâmetro de plantas de $C$. citriodora avaliado aos 240 dias após o plantio. Botucatu/SP, 2009/2010.

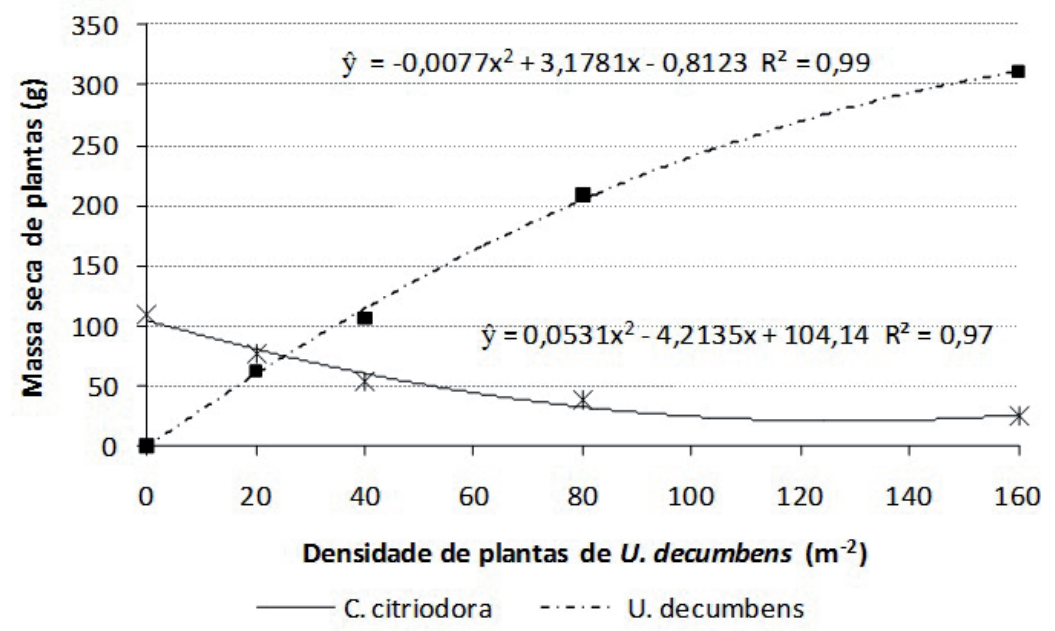

Na Tabela 2, na qual temos os valores médios de massa seca por planta, pode-se comprovar a competição intraespecífica da $U$. decumbens, já que o valor de massa seca por planta é maior quando a densidade é de 20 plantas $\mathrm{m}^{-2}$, diminuindo de acordo com o aumento de plantas, sendo o menor valor médio de massa seca de $13,88 \mathrm{~g}$ quando em convivência 160 plantas $\mathrm{m}^{-2}$.

Os resultados do presente estudo são corroborados por Toledo et al. (2001), em que a redução da altura de plantas de um clone híbrido de eucalipto no primeiro ano de convivência com $U$. decumbens foi de 27 a $51 \%$.

De acordo com Gonçalves e Benedetti (2000), a taxa de crescimento de plantas de eucalipto no campo foi pequena nos três primeiros meses após transplantio das mudas, pois esta foi a fase de estabelecimento da plantas que direciona grande quantidade de fotoassimilados e nutrientes para o crescimento das raízes para assegurar o suprimento de água e de nutrientes. Posteriormente, há uma grande expansão foliar e 
maior crescimento apical, sendo esta fase a mais sensível à competição com as plantas daninhas, pois todos os fotoassimilados estão direcionados para a formação das copas. Em situações de baixa disponibilidade de água e nutrientes, as plantas daninhas têm maior influência sobre as de eucalipto devido a seu alto poder competitivo e maior capacidade de adaptação às condições ambientais adversas (SILVA et al., 1997).

Também não houve diferença entre os incrementos em diâmetro das plantas de $C$. citriodora em convivência com $U$. decumbens nas densidades de 20 e 40 plantas $\mathrm{m}^{-2}$, sendo $40 \%$ menor que o incremento das plantas sem convivência com a plantas daninha (Tabela 2). A redução do incremento em plantas mantidas em convivência com 80 e 160 plantas $\mathrm{m}^{-2}$ foi de 63,2 e $77 \%$, respectivamente, como já observado na curva de incremento em altura, a curva do incremento em diâmetro também estabilizou nestes tratamentos (Figura 2).

De acordo com estudos realizados por Zen (1987), o diâmetro de plantas de E. grandis foi reduzido em 38 e $35,7 \%$ quando em convivência com sapé (Imperata brasiliensi Trin.) e samambaia (Pteridium aquilinum (L.) Kuhn), respectivamente, aos 28 meses após plantio das mudas de eucalipto. Corroborando estes resultados, Remor et al. (2008) verificaram redução de 51\% no diâmetro das plantas de eucalipto em convivência com plantas daninhas aos doze meses após o transplantio das mudas. Toledo et al. (2001) também observaram que a partir de 4 plantas por $\mathrm{m}^{-2}$ o capim-braquiária interferiu significativamente no crescimento inicial de mudas de eucalipto, reduzindo em média $28 \%$ o diâmetro do caule e $18 \%$ na altura das plantas aos 90 dias após o transplantio.

De acordo com Aparício et al. (2010), em estudo da matompetição em dois clones de $E$. urograndis, foi observado que o crescimento em diâmetro foi menor nos tratamentos sem controle das plantas daninhas, demonstrando maior sensibilidade à competição, atingindo valores cerca de $15 \%$ inferior ao dos tratamentos com controle. No entanto, foi evidenciado que as alturas de todos os tratamentos mantiveramse estatisticamente semelhantes ao final do experimento. Este fato pode ser explicado por as plantas de E. urograndis concentrarem suas atividades no crescimento em altura, o que dificultou o incremento em diâmetro, o qual se mostrou mais sensível à influência dos estresses bióticos e abióticos que foram submetidos.

Divergindo destes resultados ora obtidos, Cantarelli et al. (2006) não verificaram diferenças significativas entre as intensidades de controle de plantas daninhas sobre a altura e o diâmetro do colo, ou seja, um período ou dois períodos. Já, para a produtividade, esta foi significativa, inferindo-se assim que inicialmente pode não se observar diferenças no desenvolvimento, mas a convivência com a comunidade infestante refletirá em prejuízos ao final do ciclo. Já, para Costa, Alves e Pavani (2004) a Commelina benghalensis na densidade de 4 plantas. $\mathrm{m}^{-2}$ a partir dos 40 dias de convivência, com plantas de E. grandis, reduziu a área foliar, o número de folhas e as biomassas secas de ramos e folhas.

As reduções de massa seca nas plantas de C. citriodora foram significativas (Tabela 2), sendo de $29 \%$ quando em convivência com 20 plantas de $U$. decumbens $\mathrm{m}^{-2}$ e de até $77 \%$ com 160 plantas $\mathrm{m}^{-2}$. Fato este evidenciado pela média da diferença da altura das plantas, que neste tratamento quando comparado com a testemunha (livre de plantas daninhas), foi de 84 $\mathrm{cm}$. Na Figura 3 verifica-se a curva de regressão de massa seca de C. citriodora, que possui o mesmo comportamento dos demais parâmetros avaliados, ou seja, com uma tendência a se estabilizar quando em convivência com as densidades de 80 e 160 plantas $\mathrm{m}^{-2}$. 
Figura 3. Acúmulo de massa seca em plantas de $U$. decumbens $\left(\mathrm{g} \cdot \mathrm{m}^{-2}\right)$ e $C$. citriodora $\left(\mathrm{g}\right.$. planta ${ }^{-1}$ ) em função da densidade de plantas em convivência avaliado aos 240 dias após o plantio. Botucatu/SP, 2009/2010.

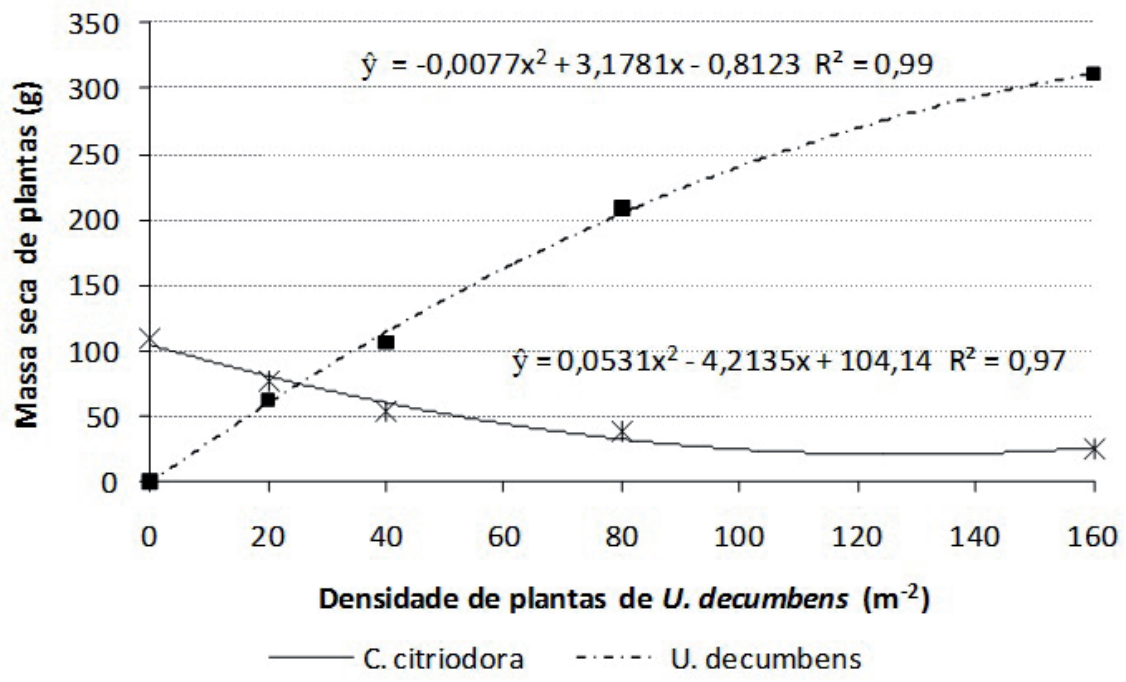

Quando se compara a massa seca das plantas de eucalipto com a das plantas de $U$. decumbens verifica-se que a partir da densidade de 20 plantas $\mathrm{m}^{-2}$ a massa das mesmas ultrapassou a das plantas de eucalipto; desta forma, pode-se concluir que a convivência com até 20 plantas $\mathrm{m}^{-2}$ de $U$. decumbens não causaria prejuízos ao eucalipto. De acordo com Cantarelli et al. (2006), existe uma correlação negativa entre biomassa de plantas daninhas e volume do $P$. taeda, ou seja, quanto maior a massa seca de plantas daninhas, menor a da espécie cultivada, ou o inverso, corroborando os resultados aqui encontrados.

A redução crescente da massa seca das plantas de $C$. citriodora em convivência com densidades de plantas de $U$. decumbens, como também a redução das outras características avaliadas neste estudo, pode ser devido a inúmeros fatores, como, por exemplo, a competição por água, sendo este um dos principais fatores responsáveis pela sobrevivência e desenvolvimento de espécies arbóreas utilizadas em reflorestamento. Pitelli et al. (1988) verificaram que os efeitos da interferência das plantas daninhas durante o primeiro ano do crescimento de Eucalyptus pellita foram mais drásticos no período de abril a setembro, quando ocorreu severa restrição hídrica na região.

De acordo com estudo realizado por Toledo et al. (2000), a densidade média do $U$. decumbens que conviveram com as plantas de eucalipto por 364 dias foi aproximadamente de 32 plantas $\mathrm{m}^{-2}$, podendo conviver com a comunidade infestante a partir do transplante dos 14 aos 28 dias, antes que a interferência se instale de maneira definitiva e reduza significativamente o seu desenvolvimento inicial, sendo denominado período anterior à interferência (PAI).

\section{Conclusão}

Nas condições em que o estudo foi desenvolvido, pode-se concluir que a planta daninha influenciou negativamente o desenvolvimento de todos os parâmetros estudados das plantas de C. citriodora, a partir de 20 plantas $^{-2}$. Já, o incremento em altura foi menor a partir de 40 plantas de $U$. decumbens $\mathrm{m}^{-2}$. A massa seca da espécie $U$. decumbens diminui de acordo com o aumento do número de plantas em convivência, demonstrando uma competição intraespecífica. 


\section{Referências}

AGOSTINETTO, D.; TAROUCO, C. P.; MARKUS, C.; OLIVEIRA, E.; SILVA, J. M. B. V.; TIRONI, S. P. Seletividade de genótipos de eucalipto a doses de herbicidas. Semina: Ciências Agrárias, Londrina, v. 31, n. 3, p. 585-598, 2010.

ANUÁRIO ESTATÍSTICO DA ASSOSSIAÇÃO DE PRODUTORES DE FLORESTAS PLANTADAS DO BRASIL - ABRAF. Anuário estatístico. 2011. Disponível em: <http://www.abraflor.org.br>. Acesso em: 11 jul. 2011.

APARÍCIO, P. S.; FERREIRA, R. L. C.; SILVA, J. A. A.; ROSA, A. C.; APARÍCIO, W. C. S. Controle da matocompetição em plantios de dois clones de Eucalyptus $\times$ Urograndis no Amapá. Ciência Florestal, Santa Maria, v. 20, n. 3, p. 381-390, 2010.

CANTARELLI, E. B.; MACHADO, S. L. O.; COSTA, E. C.; PEZZUTTI, R. Efeito do manejo de plantas daninhas no desenvolvimento inicial de Pinus taeda em várzeas na argentina. Revista Árvore, Viçosa, v. 30, n. 5, p. 711-718, 2006.

CONSTANTIN, J.; OLIVEIRAJUNIOR, R. S.; MACIEL, C. D. G. Azafenidin: novo herbicida para o controle de plantas daninhas em Eucalyptus camaldulensis. Planta Daninha, Viçosa, v. 18, n. 3, p. 405-411, 2000.

COSTA, A. G. F.; ALVES, P. L. C. A.; PAVANI, M. C. M. D. Períodos de interferência de trapoeraba (Commelina benghalensis Hort.) no crescimento inicial de eucalipto (Eucalyptus grandis W. Hill ex Maiden). Revista Árvore, Viçosa, v. 28, n. 4, p. 471-478, 2004.

EMPRESA BRASILEIRA DE PESQUISA AGROPECUÁRIA - EMBRAPA. Centro Nacional de Pesquisa de Solos. Sistema brasileiro de classificação de solos. Rio de Janeiro: Embrapa, 1999. 412 p.

GONÇALVES, J. L. M.; BENEDETTI, V. Nutrição e fertilização florestal. Piracicaba: IPEF, 2000. 427 p.

INSTITUTO DE PESQUISAS E ESTUDOS FLORESTAIS - IPEF. Chave de identificação de espécies florestais. 2004. Disponível em: <http://www.ipef.br/ identificacao/cief/especies/citriodora.asp $>$. Acesso em: 11 jul. 2011.

KISSMANN, K. G. Plantas infestantes e nocivas. São Paulo: BASF Brasileira, 1997. 825 p.

MARCHI, S. R.; PITELLI, R. A.; BEZUTTE, A. J.; CORRADINE, L.; ALVARENGA, S. F. Efeito de períodos de convivência e de controle das plantas daninhas na cultura de Eucalyptus grandis. In: SEMINÁRIO SOBRE CULTIVO MÍNIMO DO SOLO EM FLORESTAS, 1., 2002, Curitiba. Anais... Curitiba: EMBRAPA-CNPF,
2002. p. 122-133.

PEREIRA, M. R. R.; RODRIGUES, A. C. P.; CAMPOS, C. F.; MELHORANÇA FILHO, A. L.; MARTINS, D. Absorção de subdoses glyphosate aplicadas em diferentes locais de plantas de eucalipto. Revista Árvore, Viçosa, v. 35, n. 3, p. 589-594, 2011. Edição Especial.

PITELLI, R. A.; RODRIGUES, J. J. V.; KARAM, D.; COELHO, J. P.; ZANUNCIO,I.; ZANUNCIO, C .C. Efeitos de períodos de convivência e controle das plantas daninhas na cultura do eucalipto. In: SEMINÁRIO TÉCNICO SOBRE PLANTAS DANINHAS E HERBICIDAS EM REFLORESTAMENTO, 1., 1988, Rio de Janeiro. Anais... Rio de Janeiro: SBS/ ABRACAVE/SIF, 1988. p. 110-124.

RAIJ, B. van; CANTARELLA, H.; QUAGGIO, J. A.; FURLANI, A. M. C. Recomendações de adubação e calagem para o Estado de São Paulo. 2. ed. Campinas: Instituto Agronômico; Fundação IAC, 1997. 285 p. (Boletim técnico, 100).

REMOR, M. B.; TAROUCO, C. P.; OLIVEIRA, C.; SANTOS, L. S.; LEMOS, F. D.; AGOSTINETTO, D.; RAMIRO, G. A. Períodos de competição das plantas daninhas na cultura do eucalipto em função de épocas de avaliação. In: CONGRESSO DE INICIAÇÃO CIENTÍFICA, 17; ENCONTRO DE PÓSGRADUAÇÃO, 10., 2008, Pelotas. Anais... Pelotas: UFPel, 2008. p. 01-04.

SILVA, A. F.; FERREIRA, E. A.; CONCENÇO, G.; FERREIRA, F. A.; ASPIAZU, I.; GALON, L.; SEDIYAMA, T.; SILVA, A. A. Densidades de plantas daninhas e épocas de controle sobre os componentes de produção da soja. Planta Daninha, Viçosa, MG, v. 26, n. 1, p. 65-71, 2008.

SILVA, C. R.; GONÇALVES, J. L. M.; FOLEGATTI, B. S.; STAPE, J. L.; GAVA, J. L. Infestação de plantas invasoras em povoamentos de eucalipto estabelecidos nos sistemas de cultivo mínimo e intensivo no solo. Anais... In: CONFERÊNCIA IUFRO SOBRE SILVICULTURA E MELHORAMENTO DE EUCALIPTOS, 3., 1997, Salvador. Anais... Salvador: UFBA, 1997. p. 234-241.

SILVA, W.; SEDIYAMA, T.; SILVA, A. A.; CARDOSO, A. A. Índice de consumo e eficiência do uso da água em eucalipto, submetido a diferentes teores de água em convivência com braquiária. Revista Floresta, Curitiba, v. 34, n. 3, p. 325-335, 2004.

TOLEDO, R. E. B.; ALVES, P. L. C. A.; VALLE, C. F.; ALVARENGA, S. F. Estudo econômico de diferentes métodos de manejo de Brachiaria decumbens em área reflorestada com Eucalyptus grandis. Revista Árvore, Viçosa, MG, v. 20, n. 3, p. 319-330, 1996. 
TOLEDO, R. E. B.; DINARDO, W.; BEZUTTE, A. J.; ALVES, P. L. C. A.; PITELLI, R. A. Efeito da densidade de plantas de Brachiaria decumbens sobre o crescimento inicial de Eucalyptus grandis. Scientia Forestalis, Piracicaba, n. 60, p. 109-117, 2001.

TOLEDO, R. E. B.; VICTORIA FILHO, R.; PITELLI, R. A.; ALVES, P. L. C. A.; LOPES, M. A. F. Efeito de períodos de controle de plantas daninhas sobre o desenvolvimento inicial de plantas de eucalipto. Planta Daninha, Viçosa, MG, v. 18, n. 3, p. 395-404, 2000.

ZEN, S. Influência da matocompetição em plantas de Eucalyptus grandis. Série Técnica IPEF, Piracicaba, v. 4, n. 12 , p. 25-35, 1987. 
Pereira, M. R. R. et al. 